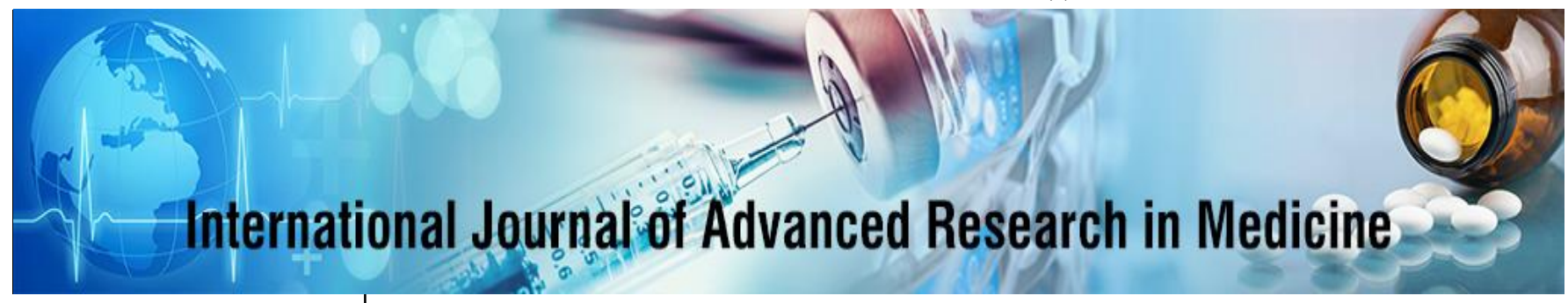

E-ISSN: 2706-9575

P-ISSN: 2706-9567

IJARM 2021; 3(1): 261-264

Received: 28-11-2020

Accepted: 16-01-2020

Dr. Sahithi Sloka Chintha

Junior resident,

Dept. of General Medicine,

Prathima Institute of Medical

Sciences, Karimnagar,

Telangana, India

Dr. G. Sukumar

Associate Professor,

Dept. of General Medicine,

RVM Institute of Medical

Sciences and Research Centre,

Delhi, India
Corresponding Author:

Dr. G. Sukumar

Associate Professor,

Dept. of General Medicine,

RVM Institute of Medical

Sciences and Research Centre,

Delhi, India

\section{An observational study on clinical profile and outcome among patients diagnosed with haemorrhagic stroke in a tertiary care centre, Telangana state}

\author{
Dr. Sahithi Sloka Chintha and Dr. G. Sukumar
}

DOI: $\underline{\text { https://doi.org/10.22271/27069567.2021.v3.i1e.147 }}$

\begin{abstract}
Introduction: Sudden onset of a neurologic deficit that is attributable to a focal vascular cause is defined as Stroke. Stroke is the second leading cause of death worldwide and one of the leading causes of disability.

Methodology: A Prospective study including patients attending outpatient department and inpatients of medicine were included in the study. The study was carried out in RVM Hospital, Siddipet district, Telangana state over a period of one year from July 2019 to July 2020.With sample size of 50 patients. Results: In this study among 50 cases, 27 are males (54\%) and 23 are females (46\%). The mean age is $54.64+12.78$ (SD).It was observed that males suffered $\mathrm{ICH}$ at younger age compared to females with $\mathrm{P}$ value of 0.041 . Basal ganglion is the commonest site involved (32\%), followed by lobar (30\%), thalamus (16\%), cerebellum (12\%) and brainstem (10\%).

Conclusion: Hypertension is found to be the major risk factor for stroke and Low GCS score, large volume of hematoma and midline shift are found to be strong predictors of poor prognosis in ICH patients.
\end{abstract}

Keywords: Stroke, Intra cranial Haemorrhage (ICH), Hypertension, Glasgow coma scale (GCS)

\section{Introduction}

Sudden onset of a neurologic deficit that is attributable to a focal vascular cause is defined as Stroke. Stroke is the second leading cause of death worldwide and one of the leading causes of disability. Strokes are classified into two i.e., ischemic or haemorrhagic. Intra cerebral haemorrhage $(\mathrm{ICH})$ is caused by bleeding directly into the brain parenchyma producing neurologic symptoms by a mass effect on neural structures or from the toxic effects of blood itself or by increasing intracranial pressure (ICP). ICH is the second most common subtype of stroke after ischemic stroke and accounts for approximately 10 to $15 \%$ of all strokes. The commonest cause of ICH is the rupture of an atheromatous artery in case of hypertensives. The most common sites of a cerebral haemorrhage are the putamen and internal capsule. Neurological deficits are usually sudden and progressive over 10-30 minutes. In India, data from major cities indicated an Annual Incidence Rate of stroke as 123 in Kolkata ${ }^{[1]}, 148$ in Mumbai ${ }^{[2]}$ and 135 in Trivandrum ${ }^{[3]}$ per 100,000 per year. The Annual Incidence Rate of stroke in India, as observed above are higher than that in United States (145-154 per 100,000 per year) ${ }^{[4]}$ and European countries $61-111$ per 100,000 per year) ${ }^{[5-7]}$. Van Asch et al., who derived their figures from a meta-analysis in 2010 concluded that the overall incidence of ICH was 24.6 per 100000 person-years ${ }^{[8]}$. Among all studies included in that meta-analysis the incidence of ICH in Asian populations has been found to be 51.8 per 100,000 personyears, which is two-fold higher than that in other ethnicities. According to the recent World Health Organisation statistical profile, stroke has been one of the leading causes of death in India over the past decade, of which ICH accounts for the majority. The major reason is that the common risk factors of stroke are not being adequately controlled. In India, 30 to 50\% estimate of early mortality in the $\mathrm{ICH}$ patients despite getting appropriate treatment. Hence the objectives of this study are 1.To study the clinical profile and to identify the various risk factors and etiological factors in patients with haemorrhagic stroke as well as the factors which determine the clinical outcome among patients with haemorrhagic stroke. 


\section{Methodology}

A Prospective observational study including patients attending outpatient department and inpatients of medicine were included in the study. The study was carried out in RVM Hospital, Siddipet district, Telangana state over a period of one year from July 2019 to July 2020. With sample size of 50 patients. Inclusion criteria: 1. Patients diagnosed as acute haemorrhagic stroke 2. Age between 20 and 80 years. Exclusion criteria: 1) Patients with traumatic haemorrhage of brain 2 . Those who are not willing to give consent. Prior to the study, approval was obtained from the Institutional Ethical Committee. Patients or the attendants were approached during the hospitalization to obtain informed and written consent. Patients or the attendants were interviewed to obtain information on the onset of stroke and any pre-existing risk factors like hypertension, diabetes mellitus, previous history of stroke and any use of medications. Statistical analysis: Patient demographics and clinical characteristics were represented as mean \pm standard deviation (SD) for continuous data, and frequency counts and percentages for categorical data variables are compared using a t-test in the case of continuous variables and a chisquare test for categorical variables. Statistical significance was considered if $\mathrm{P}<0.05$.

\section{Results}

In this study 50 cases were observed, out of that 27 are males $(54 \%)$ and 23 are females $(46 \%)$. Overall mean age is $54.64+12.78(\mathrm{SD})$. Males suffered $\mathrm{ICH}$ at younger age compared to females $51.92+11.96$ (SD) vs. $55.92+12.79$ (SD) with P-value of 0.041.

Table 1: Showing the site of haemorrhage among the study cases

\begin{tabular}{|c|c|}
\hline Site & Number of Patients $\mathbf{N = 5 0}(\boldsymbol{\%})$ \\
\hline Basal Ganglia & $(32)$ \\
\hline Thalamus & $(16)$ \\
\hline Lobar & $(30)$ \\
\hline Cerebellum & $(12)$ \\
\hline Brain stem & $(10)$ \\
\hline Total & 100 \\
\hline
\end{tabular}

Basal ganglion is the commonest site involved (32\%), followed by lobar $(30 \%)$, thalamus $(16 \%)$, cerebellum (12\%), brainstem (10\%).

Basal ganglionic bleed is the commonest in both sexes. Deep hematomas are slightly more common in men $(66.3 \%$ of total ICH in men versus $62.6 \%$ of total $\mathrm{ICH}$ in women with a P-value of 0.773 ). Lobar hematomas are slightly more common in men but this difference is also not significant with a P-value of 0.778 .

Table 2: Showing etiological factors responsible for IHD

\begin{tabular}{|c|c|}
\hline Etiology & Number of Patients \\
\hline Hypertension & 35 \\
\hline A V Malformation & 6 \\
\hline Tumors & 4 \\
\hline Unidentified & 5 \\
\hline Total & 50 \\
\hline
\end{tabular}

35 out of 50 patients $(70 \%)$ are having hypertension, 6 patients $(12 \%)$ had bleeding related to arteriovenous malformation and 4 patients $(8 \%)$ with tumour related bleeding and among $5(10 \%)$ patients the cause was unidentified.
Table 3: Showing aetiology of haemorrhage versus gender

\begin{tabular}{|c|c|c|c|}
\hline Etiology & Male & Female & Total \\
\hline Hypertension & 19 & 16 & 35 \\
\hline Arteriovenous Malformation & 4 & 2 & 6 \\
\hline Tumors & 1 & 3 & 4 \\
\hline Unidentified & 3 & 2 & 5 \\
\hline
\end{tabular}

In both men and women hypertension is the major risk factor. $70.37 \%$ of male patients and $69.56 \%$ of the female patients are having hypertension.

Table 4: Showing aetiology and site of haemorrhage

\begin{tabular}{|c|c|c|c|c|c|}
\hline Etiology & $\begin{array}{c}\text { Basal } \\
\text { Ganglia }\end{array}$ & Thalamus & & Cerebellum & Brainstem \\
\hline Hypertension & 14 & 8 & 11 & 1 & 1 \\
\hline $\begin{array}{c}\text { Arteriovenous } \\
\text { Malformation }\end{array}$ & 0 & 0 & 2 & 2 & 2 \\
\hline $\begin{array}{c}\text { Tumor } \\
\text { Related }\end{array}$ & 0 & 0 & 1 & 2 & 1 \\
\hline Unidentified & 2 & 0 & 1 & 1 & 1 \\
\hline
\end{tabular}

Majority of hypertensive had bleeds in the basal ganglionic region 14 cases, followed by lobar 11 cases and thalamic region 8 cases.

Table 5: Showing site of haemorrhage versus mortality

\begin{tabular}{|c|c|c|c|}
\hline Site & Dead & Alive & Total \\
\hline Basal Ganglia & 6 & 10 & 16 \\
\hline Thalamus & 6 & 2 & 8 \\
\hline Lobar & 4 & 11 & 15 \\
\hline Cerebellum & 2 & 4 & 6 \\
\hline Brainstem & 2 & 3 & 5 \\
\hline Total & 20 & 30 & 50 \\
\hline
\end{tabular}

Maximum mortality rate 6 out of $8(75 \%)$ is seen in thalamic region. Chi square test, when applied to find out the association between the site of haemorrhage and outcome, the result is not statistically significant with a Pvalue of 0.133 .

Table 6: Glasgow coma scale versus mortality

\begin{tabular}{|c|c|c|c|}
\hline \multirow{2}{*}{ GCS } & \multicolumn{3}{|c|}{ Outcome } \\
\cline { 2 - 4 } & Dead & Alive & Total \\
\hline$\leq 7$ & 16 & 0 & 16 \\
\hline $8-11$ & 4 & 18 & 22 \\
\hline$\geq 12$ & 0 & 12 & 12 \\
\hline Total & 20 & 30 & 50 \\
\hline
\end{tabular}

All the 16 patients with GCS $<7$ died.18 survived and 4 expired out of 22 patients with GCS level in between 8-11 followed by 12 patients with GCS > 12 survived. Mean GCS + SD for patients who survived is $16.08+4.10$ and $11.14+3.88$ for patients who died. Result is statistically significant with a P-value of $<0.0441$.

Table 7: Showing Ct characteristics versus Mortality

\begin{tabular}{|c|c|c|c|c|}
\hline CT characteristics & Yes / No & Dead & Alive & Total \\
\hline Intraventricular & Yes & 9 & 15 & 24 \\
\cline { 2 - 5 } Extension & No & 9 & 17 & 26 \\
\hline \multirow{2}{*}{ Midline Shift } & Yes & 11 & 16 & 27 \\
\cline { 2 - 5 } & No & 8 & 15 & 23 \\
\hline
\end{tabular}


In this study, 9 out of 24 patients with Intraventricular Extension and 11 out of 27 patients with Midline shift died. Chi square test is applied to find out the association between $\mathrm{CT}$ characteristics and outcome, the result is not significant with IVE $(\mathrm{P}=0.149)$ and significant with MLS $(\mathrm{P}=0.0046)$

\section{Discussion}

In this study overall mean age is $54.64+12.78$ (SD) the results are similar and comparable with studies conducted by Rathor MY et al ${ }^{[9]}$ and Qureshi A et al ${ }^{[10]}$. Other studies by Sacco S et al ${ }^{[11]}$ and Godoy D et al ${ }^{[12]}$ showed a higher mean age of incidence. Male preponderance of 27 cases $(54 \%)$ is comparable with majority of the previous studies which showed a higher proportion of male patients. However one study conducted by Sacco $\mathrm{S}$ et al ${ }^{[11]}$ showed female preponderance $(55 \%)$. Basal ganglionic region $(40 \%)$ is the commonest site of ICH followed by lobar (32\%) and thalamus (24\%). In this study, proportion of deep $\mathrm{ICH}(66.3 \%)$ is the highest, which is comparable with other studies conducted by Izumo city, Japan ${ }^{[13]}$ (69\%), Dijon, France ${ }^{[14]}(67 \%)$. In this study hypertension is the commonest risk factor constituting $70 \%$ of patients. Almost all the studies on ICH agree that systemic hypertension is the single most common risk factor. Two in-hospital based studies, one from Malaysia by Sia SF et al ${ }^{[15]}$ and another from Iran by Togha $\mathrm{M}$ et al ${ }^{[16]}$ observed similar results with hypertension being the most common risk factor $(84.8 \%$ and $65 \%$ respectively). In a meta-analysis of 11 case control studies by Ariesen M.J et al [17], all studies showed a positive association between hypertension and the risk of ICH. The overall odds ratio was 3.7. Majority of the hypertensive bleeds are in the basal ganglion (32\%). Arterial hypertension is more common in $(88.23 \%$ ) than in lobar haemorrhages $(75 \%)$, but not as much as 2-fold more common in the former than in the latter as reported in a recent review by Jackson CA et al ${ }^{[18]}$. Results of this study showed a slightly higher mean GCS score for male patients compared to females. This is comparable with similar results from studies conducted by Hsieh $\mathbf{J}$ et al $^{[19]}$ and Zahuranec $\mathrm{D}$ et al ${ }^{[20]}$. In this study, the mortality rate is very high in thalamic region (75\%) compared to other regions but it showed statistically in-significant. A recent study by Wang $\mathrm{C}$ et al ${ }^{[21]}$ done to understand the mortality predictors in ICH showed similar results as ours without any statistically significant association between outcome and location of bleed. In our study, patients with a GCS score < 7 have significantly high mortality $(100 \%)$ and the patients with GCS score > 12 had no deaths, the results showed a strong correlation between GCS at admission and patient mortality ( $\mathrm{P}$ value $<0.0441)$. Other studies by Sia Sf et al ${ }^{[15]}$ and Ahmed R et al ${ }^{[22]}$ also showed that admitting GCS has a strong statistical association with mortality. Based on this results and previous studies conducted, GCS could serve as an independent prognostic factor for poor outcome and may help clinicians to assess prognosis more accurately. Mean CT Hematoma volume was found to be a statistically significant predictor of mortality ( $\mathrm{P}$ value $<0.0012$ ) which is Similar to the observations reported by Wang $\mathrm{C}$ et al ${ }^{\text {[21] }}$ where mean CT volume is an important predictor of $\mathrm{ICH}$ mortality (P value 0.009).

\section{Conclusion}

Age related increase in the proportion of patients $(70 \%$ patients in $>40$ years age group) is observed. Male patients are predominantly affected and males suffered $\mathrm{ICH}$ at a significantly younger age compared to females. Basal Ganglion is the commonest site involved in both sexes. Hypertension is found to be the major risk factor. Low GCS score, large volume of hematoma and midline shift are found to be strong predictors of poor prognosis in $\mathrm{ICH}$ patients. CT scan is of good value in diagnosis and estimation of prognosis of ICH.

\section{References}

1. Das SK, Banerjee TK, Biswas A, Roy T, Raut DK, Mukherjee CS, et al. A prospective community-based study of stroke in Kolkata, India. Stroke. 2007; 38:90610.

2. Dalal PM, Malik S, Bhattacharjee M, Trivedi ND, Vairale J, Bhat P, et al. Population-based stroke survey in Mumbai, India: Incidence and 28-day case fatality. Neuroepidemiology. 2008;31:254-61.

3. Sridharan SE, Unnikrishnan JP, Sukumaran S, Sylaia PN, Nayak SD, Sarma PS, et al. Incidence, types, risk factors, and outcome of stroke in a developing country: The Trivandrum Stroke Registry. Stroke.2009; 40:1212-8.

4. Brown RD, Whisnant JP, Sicks JD, O'Fallon WM, Wiebers DO. Stroke incidence, prevalence, and survival: Secular trends in Rochester, Minnesota, through 1989. Stroke. 1996;27:373-80.

5. Rothwell PM, Coull AJ, Giles MF, Howard SC, Silver LE, Bull LM, et al. Change in stroke incidence, mortality, case-fatality, severity, and risk factors in Oxfordshire, UK from 1981 to 2004 (Oxford Vascular Study) Lancet. 2004; 363:1925-33.

6. Kolominsky-Rabas PL, Sarti C, Heuschmann PU, Graf $\mathrm{C}$, Siemonsen S, Neundoerfer B, et al. A prospective community-based study of stroke in Germany- The Erlanger Stroke Project (ESPro): Incidence and case fatality at 1, 3, and 12 months. Stroke. 1998;29:2501-6.

7. Syme PD, Byrne AW, Chen R, Devenny R, Forbes JF. Community-based study of stroke incidence in a Scottish population: The Scottish Borders Stroke Study. Stroke. 2005;36:1837-43.

8. Van Asch CJ, Luitse MJ, Rinkel GJ, van der Tweel I, Algra A, Klijn CJ. Incidence, case fatality, and functional outcome of intracerebral haemorrhage over time, according to age, sex, and ethnic origin: a systematic review and meta-analysis. Lancet neurology. 2010; 9(2):167-76.

9. Rathor MY, Rani MFA, Jamalludin AR, et al. Prediction of functional outcome in patients with primary intracerebral hemorrhage by clinical-computed tomographic correlations. Journal of Research in Medical Sciences: The Official Journal of Isfahan University of Medical Sciences. 2012;17(11):10561062.

10. Qureshi A, Safdar K, Weil E et al. Predictors of Early Deterioration and Mortality in Black Americans With Spontaneous Intracerebral Hemorrhage. Stroke. 1995;26(10):1764-1767. doi:10.1161/01.str.26.10.1764.

11. Sacco S, Marini C, Toni D, Olivieri L, Carolei A. Incidence and 10-Year Survival of Intracerebral Hemorrhage in a Population-Based Registry. Stroke. 2008; 40(2):

394-399.

doi:10.1161/strokeaha.108.523209. 
12. Godoy D, Pinero G, Di Napoli M. Predicting Mortality in Spontaneous Intracerebral Hemorrhage: Can Modification to Original Score Improve the Prediction?. Stroke. 2006; 37(4): 1038-1044. doi: 10.1161/01. str.0000206441. 79646.49.

13. Inagawa $\mathrm{T}$, Ohbayashi $\mathrm{N}$, Takechi A, Shibukawa $\mathrm{M}$, Yahara K. Primary Intracerebra Hemorrhage in Izumo City, Japan: Incidence Rates and Outcome in Relation to the Site of Hemorrhage. Neurosurgery. 2003; 53(6):1283-1298.

doi:10.1227/01.neu.0000093825.04365.f3.

14. Giroud M, Gras P, Chadab N, Beuriat P, Milan C, Arveux P, Dumas R.Cerebral hemorrhage in a French prospective population study. J Neurol Neurosurg Psychiatry. 1991;54:595-598.

15. Sia SF, Tan KS, Waran V. Primary intracerebral haemorrhage in Malaysia: In- hospital mortality and outcome in patients from a hospital based registry. Med J Malaysia. 2007;62:308-12.

16. Togha M, Bakhtavar K. Factors associated with inhospital mortality following intracerebral hemorrhage: a three-year study in Tehran, Iran. BMC Neurology. 2004;4(1). doi:10.1186/1471-2377-4-9.

17. Ariesen, M.J., et al., Risk factors for intracerebral hemorrhage in the general population: a systematic review. Stroke, 2003. 34(8): p. 2060-5.

18. Jackson CA, Sudlow CLM. Is hypertension a more frequent risk factor for deep than for lobar supra tentorial intracerebral haemorrhage? J Neurol Neurosurg Psychiatry. 2006;77:1244 -1252.

19. Hsieh J, Ang B, Ng Y, Allen J, King N. Comparison of Gender Differences in Intracerebral Hemorrhage in a Multi-Ethnic Asian Population. PLOS ONE. 2016;11(4):e0152945. doi:10.1371/journal.pone.0152945

20. Zahuranec D. Presentation of intracerebral haemorrhage in a community. Journal of Neurology, Neurosurgery \& Psychiatry. $\quad 2005 ; 77(3)$ 340-344. doi:10.1136/jnnp.2005.077164.

21. Wang C, Liu Y, Lee Y et al. Hematoma Shape, Hematoma Size, Glasgow Coma Scale Score and ICH Score: Which Predicts the 30-Day Mortality Better for Intracerebral Hematoma?. PLoS ONE. 2014; 9(7): e102326. doi: 10. 1371/ journal. pone.0102326.

22. Ahmed R, Shakir A, Moizuddin S et al. Predictors of in-hospital mortality for intracerebral hemorrhage: A hospital-based study in Pakistani adults. Journal of Stroke and Cerebrovascular Diseases. 2001; 10(3): 122127. Doi: 10. 1053/jscd. 2001.25462. 